\title{
Editorial \\ Microparticles as biomarkers in autoimmunity: from dust bin to center stage \\ David S Pisetsky
}

Medical Research Service, Durham VA Medical Center, Division of Immunology and Rheumatology, Duke University Medical Center, $151 \mathrm{G}$ Durham VAMC, 508 Fulton Street, Durham, NC 27705, USA

Corresponding author: David S Pisetsky, piset001@mc.duke.edu

Published: 30 November 2009

Arthritis Research \& Therapy 2009, 11:135 (doi:10.1186/ar2856)

This article is online at http://arthritis-research.com/content/11/6/135

(c) 2009 BioMed Central Ltd

See reltade research by Sellam et al., http://arthritis-research.com/content/11/5/R156

\begin{abstract}
Microparticles are small membrane-bound vesicles released from activated and dying cells. As shown in a study of primary Sjogren's syndrome, systemic lupus erythematosus and rheumatoid arthritis, levels of microparticles in the blood, as measured by a solid-phase prothrombinase assay or flow cytometry, are increased with autoimmunity. Among patients with these conditions, however, particle numbers were inversely related to disease activity and levels of the enzyme secretory phospholipase $A_{2}$ that can digest membrane lipids and perhaps cause particle loss. These findings suggest microparticles as novel biomarkers for autoimmunity, with levels reflecting events leading to their loss as well as production.
\end{abstract}

The development of biomarkers for autoimmunity is a major undertaking critical to elucidating disease pathogenesis and assessing disease activity in routine care as well as in clinical trials. In general, biomarkers represent products of cells (for example, cytokines) or phenotypic or functional changes in cells usually sampled from the blood. These changes include the expression of cell surface markers or patterns of gene expression. As shown in the previous issue of Arthritis Research and Therapy, subcellular fragments called microparticles (MPs) may represent novel biomarkers that can occupy an important place between small molecules and the cells in the hierarchy of markers [1].

MPs are small membrane-bound vesicles released from activated or dying cells. Once viewed as inert debris or cellular dust, MPs have emerged as important mediators of intercellular communication with pleiotropic activities $[2,3]$. Indeed, because of their content of lipids, proteins and nucleic acids, MPs can stimulate diverse physiologic processes such as thrombosis and the activation of immune cells, endothelial cells and fibroblasts $[2,4-6]$. The activity of MPs is impressive, perhaps related to their rich content of bioactive molecules, with their concentration in a single packet simultaneously triggering multiple signaling systems.

As markers, MPs are unusual since their origin appears to result from disparate processes. MP release thus occurs with both cell activation and cell death. This seeming paradox could result from the differences in the behavior of cell types as well as the experimental systems used to elucidate the release process. The study of particle release during activation has therefore primarily focused on platelets, while the release of particles during death has involved nucleated cells (for example, lymphocytes or monocytes) undergoing apoptosis. While nucleated cells may release particles during activation, the occurrence of activation-induced cell death may confound interpretation of this process $[7,8]$.

In their study, Sellam and colleagues used two different analytic approaches: a solid-phase assay based on the prothrombinase activity of MPs, and conventional flow cytometry. Each assay has limitations. The functional assay depends on MP capture by either annexin $\mathrm{V}$ or antibodies to cell surface molecules and is based on the assumption that all particles have prothrombinase activity; since many particles do not bind annexin, however, their presence can be missed. Similarly, flow cytometry can be limited by the small size of particles $(0.1$ to $1.0 \mu \mathrm{M})$. Depending on the thresholds for detection by flow cytometry, many particles may be missed with light scatter. Counting of MPs by staining with antibodies to cell surface markers can be problematic because the small surface area of MPs (approximately 100 to 10,000 times smaller than a cell) allows binding of miniscule amounts of antibody and leads to weak signals.

Notwithstanding these issues, Sellam and colleagues provide compelling evidence that MP levels are elevated in the

$\mathrm{MP}=$ microparticle 
plasma of patients with primary Sjogren's syndrome, systemic lupus erythematosus and rheumatoid arthritis [1]. For all three diseases, the levels of platelet MPs were the highest - and only in the plasma of patients with primary Sjogren's syndrome did levels of leukocyte MPs exceed those of controls. These results are surprising in view of evidence for extensive immune cell activation in this group of diseases [9]. The failure to demonstrate leukocyte MPs may reflect the assay systems, the patient population and the range of disease activity in patients studied.

While immune cell activation may cause MP release, the numbers may be small, with those particles released not found because of detection problems, binding to cells or clearance by macrophages/monocytes. Because of their display of cell surface markers such as phosphatidyl serine, MPs - like apoptotic cells - may be targets for phagocytic cell uptake because of their exposure of 'eat me' signals; these signals may be present even for particles from activated cells. Nevertheless, the finding of increased platelet MPs is important since these diseases all have a vascular component, with increased MPs potentially promoting thrombosis in a manner similar to that postulated for atherosclerosis, stroke and diabetes [10].

A curious aspect of Sellam and colleagues' study relates to the inverse relationship between MP numbers and disease activity. Since MP numbers are increased in the blood with autoimmune disease, the highest numbers would be expected in patients with the most active or severe disease. Instead, the authors found the opposite result, with particle numbers inversely released to extraglandular disease in primary Sjogren's syndrome, for example. Among explanations for this surprising finding, Sellam and colleagues suggest the possibility that an increase in the level of secretory phospholipase $A_{2}$ could lead particle destruction via enzymatic digestion of membrane lipids. In that case, secretory phospholipase $A_{2}$ may play an important role in homeostasis by a reducing a prothombotic and immunostimulatory blood component.

While this study raises many questions about the relationship between particle production and disease activity, it is nevertheless important in putting MPs center stage as disease markers and showing how the components in the blood can be mined in new and intriguing ways.

\section{Competing interests}

The author declares that they have no competing interests.

\section{Acknowledgements}

DSP is supported by a VA Merit Review Grant, a grant from the Alliance for Lupus Research, and NIH grant Al083923.

\section{References}

1. Sellam J, Proulle V, Jungel A, Ittah M, Miceli-Richard C, Gottenberg JE, Toti F, Benessiano J, Gay S, Freyssinet JM, Mariette X: Increased levels of circulating microparticles in primary Sjögren's syndrome, systemic lupus erythematosus and rheuma- toid arthritis and relation with disease activity. Arthritis Res Ther 2009, 11:R156.

2. Distler JH, Pisetsky DS, Huber LC, Kalden JR, Gay S, Distler O: Microparticles as regulators of inflammation: novel players of cellular crosstalk in the rheumatic diseases. Arthritis Rheum 2005, 52:3337-3348.

3. Piccin A, Murphy WG, Smith OP: Circulating microparticles: pathophysiology and clinical implications. Blood Rev 2007, 21: 157-171.

4. Mesri M, Altier DC: Leukocyte microparticles stimulate endothelial cell cytokine release and tissue factor induction in a JNK1 signaling pathway. J Biol Chem 1999, 274:2311123118.

5. Ratajczak J, Wysoczynski M, Hayek F, Janowska-Wieczorek A Ratajczak MZ: Membrane-derived microvesicles: important and underappreciated mediators of cell-to-cell communication. Leukemia 2006, 20:1487-1495.

6. Martinez MC, Larbret F, Zobairi F, Coulombe J, Debili N, Vainchenker W, Ruat M, Freyssinet JM: Transfer of differentiation signal by membrane microvesicles harboring hedgehog morphogens. Blood 2006, 108:3012-3020.

7. Lynch SF, Ludlam CA: Plasma microparticles and vascular disorders. Br J Haematol 2007, 137:36-48.

8. Distler JHW, Huber LC, Hueber AJ, Reich CF, Gay S, Dister O, Pisetsky DS: The release of microparticles by apoptotic cells and their effects on macrophages. Apoptosis 2005, 10:731741.

9. Liu CC, Ahearn JM: The search for lupus biomarkers. Best Pract Res Clin Rheumatol 2009, 23:507-523.

10. VanWijk MJ, VanBavel E, Sturk A, Nieuwland R: Microparticles in cardiovascular diseases. Cardiovasc Res 2003, 59:277-287. 